\title{
PERSENTASE MALOKLUSI PADA ANAK AUTIS DAN ANAK NORMAL DI KOTA MEDAN
}

\author{
(PERCENTAGE OF MALOCCLUSION IN AUTIS AND NORMAL \\ CHILDREN IN MEDAN)
}

\author{
Essie Octiara, Zilda Fahnia
}

Departemen Ilmu Kedokteran Gigi Anak

Fakultas Kedokteran Gigi, Universitas Sumatera Utara

Jl. Alumni No.2, Kampus USU, Medan

\begin{abstract}
The aim of this descriptive survey was to know the percentage of malocclusion based on Angle classification and Dental Aesthetic Index in 50 autis and 50 normal children aged 6-11 years old. Autistic child samples were taken by total sampling in two SLB and three foundation therapis, where as normal children taken from two public schools in Medan, that was matching based on aged and sex. Collecting data was done with clinical examination. The result showed that percentage of malocclusion in autis children was $86 \%$ and $76 \%$ in normal children. In autis children percentage of malocclusion Class I 48\%, Class II 26\% and Class III $12 \%$. In normal children percentage of malocclusion Class I 60\%, Class II $6 \%$ and Class III 10\%. General feature of malocclusion in mixed dentition was $46,42 \%$ crowded in autis, where as normal children was protrusive $41,37 \%$. The largest componen DAI of mixed dentition period was crowding $81,81 \%$ in autis and $71,42 \%$ in normal children. In conclusion, the percentage of malocclusion in autis and normal child were more high compare normal occlusion.
\end{abstract}

Key words: autism children, normal children, prevalence of malocclusion, orthodontic treatment

\begin{abstract}
Abstrak
Tujuan penelitian survei deskriptif ini adalah untuk mengetahui persentase maloklusi berdasarkan klasifikasi Angle dan Dental Aesthetic Index pada 50 anak autis dan 50 anak normal usia 6-18 tahun. Sampel anak autis diambil dengan cara total sampling pada 2 SLB dan 3 yayasan terapi, sedangkan anak normal diambil dari 2 buah sekolah umum di Medan yang dipadankan berdasarkan usia dan jenis kelamin anak autis. Metode pengumpulan data dilakukan dengan pemeriksaan klinis. Hasil penelitian menunjukkan persentase maloklusi pada anak autis adalah $86 \%$ dan anak normal 76\%. Pada anak autis persentase maloklusi Klas I 48\%, Klas II 26\% dan Klas III 12\%. Pada anak normal, maloklusi Klas I $60 \%$ dan Klas II $6 \%$ dan Klas III $10 \%$. Gambaran umum maloklusi periode gigi bercampur pada anak autis adalah gigi berjejal $46,42 \%$, sedangkan pada anak normal protrusi $41,37 \%$. Komponen DAI periode gigi permanen yang terbanyak pada anak autis adalah gigi berjejal $81,81 \%$ dan anak normal $71,42 \%$. Sebagai kesimpulan, persentase maloklusi lebih banyak diderita anak autis dan anak normal dibanding oklusi normal.
\end{abstract}

Kata kunci: anak autis, anak normal, prevalensi maloklusi, kebutuhan perawatan orto

\section{PENDAHULUAN}

Autis merupakan suatu kondisi gangguan perkembangan yang sangat kompleks, biasanya telah terlihat sebelum anak berusia 3 tahun. Penyandang autis menunjukkan gangguan komunikasi, interaksi sosial dan perilaku. Mereka tidak mampu menjalin hubungan sosial dan berkomunikasi normal, sehingga terisolasi dari kontak manusia dan tenggelam dalam dunianya sendiri. ${ }^{1-3}$

Anak autis juga sering disertai adanya ketidak- mampuan untuk bermain spontan dan imajinatif, kurangnya fungsi sensori dan motorik, pemilih dalam hal makanan, cenderung bermasalah dengan pencernaan sehingga asupan terbatas dan mengalami gangguan tidur. Etiologi autis belum diketahui secara pasti, kebanyakan ilmuwan percaya bahwa autis disebabkan faktor genetik.,5 Beberapa teori menjelaskan faktor-faktor yang mempengaruhi terjadinya autis yaitu: faktor biologi, ${ }^{6}$ imunologi, ${ }^{7}$ neuroanatomi, ${ }^{7,8}$ biokemikal, ${ }^{9}$ dan prenatal. ${ }^{7}$

Dalam dekade terakhir ini jumlah anak yang ter- 
kena autis semakin meningkat pesat diberbagai belahan dunia. Pertambahan anak autis di Kanada dan Jepang mencapai $40 \%$ sejak tahun 1980. Menurut Center for Disease Control di Amerika Serikat, perbandingan anak autis mencapai 1 anak per 80 kelahiran, sementara itu di Thailand seperti yang dilaporkan oleh Institut Nasional Kesehatan Anak Queen Sirikit, persentase autis mengalami peningkatan dari 1,43/10.000 pada tahun 1988 menjadi 6,94/10.000 pada tahun 2002. Penderita autis mencapai 7000 orang (Depkes 2004) di Indonesia. Berdasarkan pendataan yang dilakukan oleh Forum Masyarakat Peduli Autis (FMPA) pada April 2012 jumlah anak autis di Sumatera Utara berkisar 1000 orang. Jumlah anak autis yang lahir di Kota Medan diperkirakan mencapai 250 orang pertahun dan akan terus bertambah dari tahun ke tahun. ${ }^{3-5}$

Pada anak autis ditemukan kondisi higiene oral yang buruk serta menunjukkan angka penyakit periodontal dan karies yang cukup tinggi. Hasil penelitian mengenai kondisi gigi pada anak-anak di Chennai, India menunjukkan bahwa anak-anak berkebutuhan khusus memiliki kebersihan rongga mulut yang rendah, prevalensi karies yang tinggi, dan gingivitis yang sedang. Karies yang tidak dirawat serta kehilangan gigi yang terlalu cepat akan membuat risiko terjadinya maloklusi. Penelitian Luppanapornlap pada anak autis berusia 3-5 tahun di Queen Sirikit National Institute menunjukkan lebih dari setengah subjek penelitian memiliki kondisi rongga mulut yang buruk dan angka karies yang tinggi. ${ }^{8}$ Karies dapat menyebabkan terjadinya kehilangan gigi secara dini dan akhirnya dapat menimbulkan maloklusi. Penelitian ini juga menunjukkan persentase yang tinggi terjadinya diastema, overjet, dan gigitan terbuka. ${ }^{8}$ Masalah maloklusi kemungkinan juga berhubungan dengan kebiasaan pasien seperti, mengisap jari, menggigit kuku dan benda asing yang merusak gigi. Selain itu, kebiasaan makan makan makanan yang lunak dan koordinasi otot yang lemah membuat anak tidak suka mengunyah makanan, hal ini berpengaruh terhadap perkembangan rahang anak yang kemungkinan besar berakibat terjadinya gigi berjejal. ${ }^{3,8,9}$

Maloklusi merupakan bentuk menyimpang dari bentuk standar yang diterima sebagai bentuk normal. Maloklusi juga berarti kelainan ketika gigigeligi atas dan bawah saling bertemu saat oklusi. Maloklusi memberikan gangguan terhadap penampilan estetis, berbicara atau kenyamanan dalam mengunyah makanan. ${ }^{5}$

Tujuan penelitian ini adalah mengetahui persentase maloklusi berdasarkan klasifikasi Angle dan Dental Aesthetic Index (WHO) pada anak autis dan anak normal usia 6-18 tahun dan melihat kebutuhan pe- rawatan maloklusi di Kota Medan.

\section{BAHAN DAN METODE}

Jenis penelitian adalah survei deskriptif. Jumlah sampel adalah 50 orang anak autis usia 6-18 tahun yang di ambil secara total sampling dari SLB dan Yayasan Terapi Kota Medan, dan 50 orang anak normal usia 6-18 tahun yang diambil secara matching berdasarkan usia dan jenis kelamin di Sekolah Angkasa Kecamatan Medan Polonia dan Sekolah Taman Pendidikan Islam Kecamatan Medan Amplas. Kriteria inklusi adalah anak tidak sedang dalam perawatan orto dan memiliki minimal satu hubungan gigi molar satu permanen atau kaninus permanen. Pengumpulan data yang dilakukan pada gigi bercampur menggunakan Klasifikasi Angle dan gambaran maloklusi (gigi berjejal, rotasi, protrusi, diastema, gigitan terbuka, gigitan terbalik dan gigitan dalam). Pada periode gigi permanen menggunakan Klasifikasi Angle dan Dental Aesthetic Index.

\section{HASIL}

Pada Tabel 1 terlihat jumlah subjek penelitian pada periode gigi bercampur untuk anak autis yaitu sebanyak 28 orang anak (54\%) dan anak normal 29 orang anak (58\%), sedangkan pada periode gigi permanen untuk anak autis sebanyak 22 orang anak $(46 \%)$ dan anak normal 21 orang anak (42\%). Berdasarkan jenis kelamin, subjek penelitian didominasi oleh laki-laki sebesar $88 \%$.

Tabel 1. Persentase responden berdasarkan usia dan jenis kelamin

\begin{tabular}{cccc}
\hline & \multicolumn{2}{c}{ Kelompok } & \\
\cline { 2 - 3 } Karakteristik & $\begin{array}{c}\text { Autis }(\mathrm{n}=50) \\
\mathrm{n}(\%)\end{array}$ & $\begin{array}{c}\text { Normal }(\mathrm{n}=50) \\
\mathrm{n}(\%)\end{array}$ & Total \\
\hline Jenis kelamin & & & \\
Laki-laki & $44(88)$ & $44(88)$ & 88 \\
Perempuan & $6(12)$ & $6(12)$ & 12 \\
\hline Periode gigi & & & \\
Bercampur & $28(54)$ & $29(58)$ & 56 \\
Permanen & $22(46)$ & $21(42)$ & 44 \\
\hline
\end{tabular}

Persentase oklusi menurut Klasifikasi Angle pada anak autis adalah oklusi Klas I/ normal (tanpa disertai gigi berjejal, protrusi, dan lain-lain) sebanyak 7 orang anak (14\%) dan maloklusi Klas I (disertai gigi berjejal, protrusi dan lain-lain) sebanyak 24 orang anak (48\%), maloklusi Klas II sebanyak 13 orang anak (26\%) dan maloklusi Klas III sebanyak 6 orang anak (12\%). Persentase oklusi menurut Klasifikasi Angle pada anak normal adalah oklusi normal Klas I sebanyak 12 orang anak (24\%) dan 
maloklusi Klas I 30 orang anak (60\%), maloklusi Klas II 3 orang anak (6\%) dan maloklusi Klas III sebanyak 5 orang anak (10\%) (Tabel 2).

Anak autis pada periode gigi bercampur, diperoleh gambaran maloklusi terbanyak adalah gigi berjejal sebanyak 13 orang anak $(46,42 \%)$, sedangkan pada 29 orang anak normal didapatkan gambaran maloklusi terbanyak yaitu protrusi sebanyak 12 orang anak (41,37\%) (Tabel 3).

Distribusi komponen DAI pada 22 orang anak autis periode gigi permanen terbanyak adalah gigi berjejal sebanyak 18 anak (81,81\%). Distribusi komponen DAI pada 21 orang anak normal terbanyak adalah gigi berjejal sebanyak 15 anak (71,42\%) (Tabel 4).

Distribusi skor DAI pada 22 orang anak autis paling banyak adalah maloklusi yang sangat parah dan sangat memerlukan perawatan ortodonti sebanyak 8 orang anak (36,36\%). Pada anak normal skor DAI paling banyak adalah maloklusi ringan dan tidak perlu perawatan ortodonti sebanyak 14 orang anak $(66,66 \%)$ (Tabel 5).

Tabel 2. Persentase oklusi pada anak autis dan normal berdasarkan klasifikasi Angle periode pertumbuhan gigi

\begin{tabular}{|c|c|c|c|c|c|c|}
\hline \multirow{3}{*}{$\begin{array}{l}\text { Klasifikasi oklusi } \\
\text { (Angle) }\end{array}$} & \multicolumn{6}{|c|}{ Kelompok } \\
\hline & \multicolumn{3}{|c|}{$\begin{array}{l}\text { Autis } \\
(\mathrm{n}=50)\end{array}$} & \multicolumn{3}{|c|}{$\begin{array}{l}\text { Normal } \\
(\mathrm{n}=50)\end{array}$} \\
\hline & $\begin{array}{c}\text { Gigi bercampur } \\
\mathrm{n}(\%)\end{array}$ & $\begin{array}{c}\text { Gigi permanen } \\
\mathrm{n}(\%)\end{array}$ & $\begin{array}{l}\text { Total } \\
\mathrm{n}(\%)\end{array}$ & $\begin{array}{c}\text { Gigi bercampur } \\
\mathrm{n}(\%)\end{array}$ & $\begin{array}{c}\text { Gigi permanen } \\
\mathrm{n}(\%)\end{array}$ & $\begin{array}{l}\text { Total } \\
\mathrm{n}(\%)\end{array}$ \\
\hline Oklusi normal & $7(14)$ & 0 & 7 (14) & $8(16)$ & $4(8)$ & $12(24)$ \\
\hline \multicolumn{7}{|l|}{ Maloklusi: } \\
\hline Klas I & $12(24)$ & $12(24)$ & $24(48)$ & $16(32)$ & $14(28)$ & $30(60)$ \\
\hline Klas II & $8(16)$ & $5(10)$ & $13(26)$ & $2(4)$ & $1(2)$ & $3(6)$ \\
\hline Klas III & $1(2)$ & $5(10)$ & $6(12)$ & $3(6)$ & $2(4)$ & $5(10)$ \\
\hline
\end{tabular}

Tabel 3. Distribusi gambaran maloklusi periode gigi bercampur pada anak autis dan normal

\begin{tabular}{lcc}
\hline \multirow{2}{*}{ Gambaran maloklusi } & \multicolumn{2}{c}{ Kelompok } \\
\cline { 2 - 3 } & Autis $(\mathrm{n}=28)$ & $\mathrm{Normal}(\mathrm{n}=29)$ \\
$\mathrm{n}(\%)$
\end{tabular}

Tabel 4. Distribusi komponen DAI pada periode gigi permanen anak autis dan normal

\begin{tabular}{llc}
\hline \multirow{2}{*}{ Komponen DAI } & \multicolumn{2}{c}{ Kelompok } \\
\cline { 2 - 3 } & $\begin{array}{c}\text { Autis }(\mathrm{n}=22) \\
\mathrm{n}(\%)\end{array}$ & $\begin{array}{c}\text { Normal }(\mathrm{n}=21) \\
\mathrm{n}(\%)\end{array}$ \\
\hline Gigi hilang $(\geq 1)$ & 0 & 0 \\
Gigi berjejal/rotasi/ (1 atau 2 segmen) & $18(81,81)$ & $15(71,42)$ \\
Ruang antar gigi $(1$ atau 2 segmen) & $1(4,54)$ & $2(9,52)$ \\
Diastema sentralis $(\geq 1 \mathrm{~mm})$ & $2(9,09)$ & $3(14,28)$ \\
Ketidakteraturan terparah anterior maksila $(\geq 1 \mathrm{~mm})$ & $15(68,18)$ & $10(47,61)$ \\
Ketidakteraturan terparah anterior mandibular $(\geq 1 \mathrm{~mm})$ & $10(45,45)$ & $9(42,85)$ \\
Jarak gigit anterior maksila $(\geq 3 \mathrm{~mm})$ & $9(40,90)$ & $8(38,09)$ \\
Jarak gigit anterior mandibular $(\geq 1 \mathrm{~mm})$ & $5(22,72)$ & $1(4,76)$ \\
Gigitan terbuka anterior $(\geq 1)$ & $4(18,18)$ & $2(9,52)$ \\
Relasi molar anteroposterior $(\geq 1 / 2$ cusp) & $10(45,45)$ & $3(14,28)$ \\
\hline
\end{tabular}


Tabel 5. Distribusi skor DAI dan kebutuhan perawatan pada periode gigi permanen anak autis dan normal

\begin{tabular}{llcc}
\hline \multirow{2}{*}{ Skor DAI,Tingkat Keparahan dan Kebutuhan Perawatan } & \multicolumn{2}{c}{ Kelompok } \\
\cline { 2 - 3 } & Autis n (\%) & Normal n (\%) \\
\hline 26-30 Maloklusi sedang, beberapa perlu perawatan ringan & $6(27,28)$ & $14(66,66)$ \\
31-35 Maloklusi parah, perlu perawatan & $4(18,18)$ & $5(23,80)$ \\
$\geq 36 \quad$ Maloklusi yang sangat parah sangat memerlukan perawatan & $4(18,18)$ & $1(4,77)$ \\
\multicolumn{2}{c}{ Total Jumlah } & $8(36,36)$ & $1(4,77)$ \\
\hline
\end{tabular}

\section{PEMBAHASAN}

Hasil penelitian ini menunjukkan persentase maloklusi pada anak autis cukup tinggi yaitu $86 \%$. Hasil penelitian ini sesuai dengan penelitian yang dilakukan oleh Muppa et al (2013) di India, didapati persentase maloklusi anak autis sebesar $82 \% .^{10}$ Tingginya persentase maloklusi pada anak autis mungkin akibat ketidakmampuan dalam menjaga kebersihan rongga mulut, sehingga risiko terjadinya karies, penyakit periodontal dan kehilangan gigi secara dini, selain itu anak autis juga memiliki kebiasaan buruk seperti menggigit kuku, menggigit jaringan lunak mulut dan bruksism yang merupakan salah satu faktor risiko terjadi maloklusi. $3,5,8,11$

Persentase maloklusi pada anak normal pada penelitian ini lebih rendah dibandingkan anak autis yaitu $76 \%$ dibanding $86 \%$. Penelitian ini serupa dengan penelitian yang dilakukan Luppanapornlarp, persentase maloklusi anak autis lebih tinggi $(62,5 \%)$ dibandingkan anak normal $(52,1 \%){ }^{8}$

Pada periode gigi bercampur, baik pada anak autis maupun pada anak normal tidak ada perbedaan persentase maloklusi yaitu sebesar $42 \%$, namun hal ini berbeda pada periode gigi permanen. Pada gigi permanen maloklusi anak autis sebesar $44 \%$, sedangkan pada anak normal $34 \%$. Pada periode gigi bercampur sering terjadi perubahan kecepatan dan arah pertumbuhan gigi geligi serta tulang rahang, sehingga kemungkinan terjadi relasi gigi geligi menjadi malposisi atau maloklusi atau malah sebaliknya. ${ }^{12}$ Kelainan dentokraniofasial anak yang terjadi pada masa gigi bercampur dapat bersifat sementara dan tidak diperlukan perawatan dan dibuktikan dengan terkoreksinya kelainan tersebut pada periode gigi permanen, namun dapat juga bersifat tetap dan memerlukan perawatan orto secara dini., ${ }^{4}, 13$

Pada anak autis, maloklusi pada periode gigi permanen lebih tinggi dibandingan periode gigi bercampur, kemungkinan maloklusi pada periode gigi bercampur cenderung menetap bahkan meningkat pada periode gigi permanen. Hal ini disebabkan anak autis memiliki beberapa faktor risiko terjadinya maloklusi yang bila tidak dikoreksi dan tidak dilakukan perawatan dapat menyebabkan maloklusi atau malposisi yang menetap pada gigi geligi permanen. Literatur mengemukakan periode pertumbuhan gigi mempengaruhi maloklusi, dengan asumsi tidak berkembangnya rahang anak autis karena lemahnya otot pengunyahan yang menyebabkan anak autis lebih suka menyimpan makanan didalam mulut dan menelannya., ${ }^{3,14}$ Disamping itu, kemungkinan juga dapat disebabkan oleh peningkatan terjadinya karies dan kebiasaan buruk yang tidak dihilangkan pada anak autis memperburuk susunan gigi seiring dengan bertambahnya usia. ${ }^{3}$ Dalam periode gigi bercampur, untuk mengurangi maloklusi dapat dilakukan tahap perawatan preventif, interseptif atau kuratif ortodonti atau kombinasi. ${ }^{4,14}$

Menurut klasifikasi Angle, klasifikasi maloklusi pada anak autis yang terbanyak adalah Klas I sebesar $48 \%$, Klas II sebesar 26\%, Klas III sebesar $12 \%$. Hal ini sesuai dengan literatur yang memuat berbagai penelitian dari berbagai negara yang menemukan bahwa prevalensi Klas I lebih besar dibandingkan Klas II dan Klas III. ${ }^{15}$

Berdasarkan gambaran maloklusi secara umum pada periode gigi bercampur, maloklusi pada anak autis berbeda dengan anak normal. Pada anak autis empat gambaran maloklusi paling banyak adalah gigi berjejal $(46,42 \%)$, gigitan dalam $(32,14 \%)$, gigitan terbalik $(25 \%)$ dan protrusi $(17,85 \%)$. Gigi berjejal pada periode gigi bercampur dapat disebabkan terjadinya ketidakseimbangan antara mesio distal gigi dengan lengkung rahang. Hal ini akibat kehilangan dini gigi desidui sehingga ruang untuk erupsi gigi berkurang, selain itu juga disebabkan karena jalannya erupsi gigi yang menyimpang. 3,7

Pada anak normal, empat gambaran maloklusi pada periode gigi bercampur paling banyak adalah protrusi sebesar $41,37 \%$, diikuti dengan gigi berjejal $34,48 \%$, gigitan dalam $31,03 \%$ dan gigitan terbalik $20,68 \%$. Protrusi dapat dipengaruhi oleh keturunan, kebiasaan mendorong lidah ke depan serta bernapas melalui mulut dan kebiasaan buruk menghisap ibu jari. ${ }^{16}$

Empat komponen DAI yang paling banyak dimiliki oleh anak autis pada periode gigi permanen adalah gigi berjejal/rotasi/ keluar dari lengkung rahang sebesar $81,81 \%$, ketidakteraturan terparah an- 
terior maksila $68,18 \%$, ketidakteraturan terparah pada mandibula $45,45 \%$ dan relasi molar anteroposterior $45,45 \%$. Tingginya penyakit periodontal dan kehilangan gigi yang terlalu dini menyebabkan gigi berjejal, sedangkan tidak berkembangnya rahang yang disebabkan kemampuan otot dan kebiasaan makan makanan lunak menyebabkan hubungan rahang menjadi tidak normal. ${ }^{5,17}$

Empat komponen DAI paling banyak yang dimiliki oleh anak normal pada periode gigi permanen adalah gigi berjejal/ rotasi/ keluar dari lengkung rahang $71,42 \%$, ketidakteraturan terparah anterior pada maksila $47,61 \%$, ketidakteraturan terparah anterior pada mandibula $42,85 \%$ dan jarak gigit anterior maksila 38,09\%. Gigi berjejal adalah gambaran maloklusi paling umum dari berbagai penelitian. Gigi berjejal terjadi akibat tidak harmonisnya ukuran gigi dan panjang lengkung rahang misalnya ukuran gigi yang terlalu besar, lengkung rahang yang terlalu pendek atau jumlah gigi lebih dari normal., ${ }^{5}$

Pada penelitian ini kebutuhan perawatan pada anak autis paling tinggi adalah maloklusi yang sangat parah dan sangat memerlukan perawatan sebesar $36,36 \%$, normal/maloklusi ringan dan tidak memerlukan perawatan $27,28 \%$, maloklusi sedang dan beberapa perlu perawatan $18,18 \%$, maloklusi parah dan perlu perawatan 18,18\% (Tabel 5). Hasil yang sama juga ditemukan pada penelitian yang dilakukan oleh Luppanapornlarp dan Leelataweewud, penelitian tersebut mendapatkan $37,5 \%$ anak autis memiliki maloklusi berat hingga sangat berat yang sangat membutuhkan perawatan. ${ }^{8}$

Pada anak normal kebutuhan perawatan yang paling tinggi adalah maloklusi ringan dan tidak perlu perawatan sebesar $66,66 \%$, maloklusi sedang dan perlu perawatan ringan $23,80 \%$, maloklusi parah dan perlu perawatan sebanyak $4,77 \%$ dan maloklusi yang sangat parah dan sangat memerlukan sebanyak 4,77\% (Tabel 5). Hasil penelitian ini mirip dengan penelitian Garbin yaitu maloklusi ringan dan tidak memerlukan perawatan sebesar $65,26 \%$, maloklusi sedang dan perlu perawatan ringan $12,81 \%$, maloklusi parah dan perlu perawatan sebanyak $10,90 \%$, maloklusi sangat parah dan sangat memerlukan perawatan sebanyak $11,03 \%{ }^{17}$

Sebagai kesimpulan, persentase maloklusi lebih banyak diderita oleh anak autis dan anak normal daripada oklusi normal. Indeks DAI dengan komponen normal/maloklusi ringan dan tidak perlu perawatan paling banyak dimiliki oleh anak normal, sebaliknya pada anak autis banyak memiliki maloklusi yang sangat parah dan sangat memerlukan perawatan.

\section{Daftar Pustaka}

1. Syarif W. Kiat sukses menangani pasien handicapped dalam praktek dokter gigi. Dalam: Persatuan Dokter Gigi Indonesia, ed. Prosiding Bandung Dentistry 8. Bandung, 2008: 258-9.

2. Kaplan HI, Sadock BJ, Sadock VA. Synopsis of psychiatry behavioral sciences clinical psychiatry..$^{\text {th }}$ ed., Philadelphia: Lippincott Williams \& Wilkins Co, 2003: 1209-22.

3. Rekha VC, Arangannal P, Shahed H. Oral health status children with autistic disorder in Chenai. European Archive Paediatric Dentistry 2012; 13: 126-31.

4. Scully C, Cawson RA. Medical problems dentistry. $5^{\text {th }}$ ed., New Delhi: Replika Press Pvt. Ltd, 2005: 422-3.

5. Jaber MA. Dental caries experience, oral health status and treatment needs of dental patiens with autis. J Appl Oral Sciene 2011; 19: 212-16.

6. Halgin RP, Whitbourne SK. Abnormal psychology clinical perspective on psychological disorder. $6^{\text {th }}$ ed., Philadelpia: Times Mirror Higher Education Group, 2009: 344-7.

7. Rashid Mayyadah H, Al-Jubouri Raja H. Evaluation of oral health status in a sample of autistic male children. J Bagh College Dent 2012; 24(2):62-4.

8. Luppanapornlarp S, Leelataweewud P, Putongkam P. Periodontal status and orthodontic treatment need of autistic children. World J Orthod 2010; 11: 256-61.

9. Vajawat M, Deepika PC. Comparative evaluation of oral hygiene practices and oral health status in autistic and normal individuals. J Int Soc Prev Community Dent 2012; 2(2): 58-62.

10. Muppa R, Bhupathiraju P, Duddu MK. Prevalence and determinant factors of malocclusion in population with special needs in South India. J of Indian Society of Pedodontics and Preventive Dentistry 2013; 31: 87-90.

11. Murshid EZ. Diet, oral hygiene practices and dental health in autistic children in Riyadh, Saudi Arabia. OHDM 2014; 13: 91-6.

12. Muniroh SM. Dinamika resiliensi orangtua anak autis. J Pendidikan 2010; 7: 1-15.

13. Garbin A, Paulo CP, Fernando L. Malocclusion prevalence and comparison between the Angle classifycation and the Dental Aesthetic Index in scholars in the Interior Sao Paulo State-Brazil. Dental Press J Orthod. 2010; 15(4): 94-102.

14. Khanna S, Gharpure AS. Determination of sel satisfaction with dental appearance and oral health status among a population of dentate adults in a referral institution. British J Medicine Medical Research 2014; 4(14): 2725-35.

15. Marya CM. A textbook of public heatlh dentistry. $1^{\text {st }}$ ed., New Delhi: Jaypee Brothers Medical Publishers., 2011; 190-2. 
16. Richa, Yashoda Y, Punarik MP. Oral health status and parental perception of child oral health related quality-of-life of children with autis in Bangalore, India J Indian Soc of Pedod and Preventive
Dentistry 2014; 32(2): 135-9.

17. Chadha GM, Kakodkar P, Chaugule V. Dental survey of institutionalized children with autistic disorder. Int J Clin Pediatr Dent 2012; 5(1): 29-32. 